\title{
Opening the enforcement of EU fundamental values to European citizens
}

VB verfassungsblog.de/opening-the-enforcement-of-eu-fundamental-values-to-european-citizens/

Marco Dani So 7 Apr 2013

So 7 Apr 2013

Over the last two years, the adoption, implementation and, more recently, amendment of the new Hungarian Constitution have sparked widespread political and academic discussion motivated by the controversial genesis and contents of that document. Debates on a European scale have revolved around the difficulties encountered by the European Union in contrasting the corrosion of constitutional democracy in one of its member states. Following a consolidated trend in European studies, also in this occasion the blame has been thrown on the EU institutional framework. If there are problems, it seems, this is mainly because the available instruments of enforcement are inadequate. Jan-Werner Müller's proposal for a new institution - provisionally baptised "Copenhagen Commission" - does not make exception. He argues that the available remedies (article 7 TEU, infringement proceedings, etc) are not usable or are scarcely effective, and that what we need is a new EU body entrusted with the task of monitoring and sanctioning member states in case of egregious violations of the European fundamental values enshrined in article 2 TEU. The contours of this proposal are only sketched and, therefore, it is difficult to engage in a specific discussion. However, already from what we know it is possible to say that the idea of a Copenhagen Commission has the merit of opening an interesting debate by addressing some of the limits of the current EU institutional architecture.

But prior to discussing this proposal and adventuring myself into institutional engineering, a premise is in order. Before putting forward proposals for institutional reform, we should be aware that the corrosion of European constitutional culture and, notably, of the idea of a pluralist constitution is a phenomenon extending well beyond the Hungarian case. This is not just because other member states can be similarly charged for their dubious commitment to constitutional democracy. More critically, the EU itself is deeply implicated in a political and legal culture which sits at odds with the idea of a pluralist constitution. Already Floris de Witte and Jan Komárek have hinted to the fact that the EU latest institutional developments associated with the management of the Eurocrisis impose remarkable constraints on national constitutional democracies without offering equivalent substitutes at EU level. To this argument, I would only add that the corrosion of the idea of a pluralist constitution in the EU is connected with the hegemony of the post-political vision, a new common sense in which the core normative claims of pluralist constitutions - legitimating and mediating social and political conflicts - are largely discredited.[1] I do not have space here to elaborate this argument, [2] but I think it is important to stress it. Prior to being institutional, the challenges we are facing are cultural in a deep sense. If we want to be serious in defending constitutional democracy, we cannot target exclusively Hungary or some other deranging member state. We need to question comprehensively European public law, its emerging legal and political culture and its capacity to establish or, at least, respect constitutional democracy. At the end of the day, even the best of the proposals for institutional reform will fail if the EU is not perceived as a credible bearer of liberal democratic ideals.

Having said this, let's turn to institutional fixes. In order to discuss the idea of a Copenhagen Commission, we should first of all clarify the requirements of a viable system of enforcement of EU values. Arguably, there are at least two requisites on which all should more or less agree. The first is the impartiality and fairness of the institutions and procedures involved in enforcement. What we expect is that the acting body be independent, high profile, politically unbiased. In our field, this institution should be able to strike a fair balance between the respect of the values enshrined in article 2 TEU and national constitutional identity. A second requirement goes to the effectiveness of enforcement: the envisaged mechanism must exert sufficient pressure to draw unruly countries in a process of constitutional self-examination which, ideally, should induce them to reconsider their misguided political initiatives. There is then a third requirement concerning civic engagement. Admittedly, this is a more debatable one given that respect of EU values has traditionally been conceived of as a matter between EU institutions and member states. However, also European citizens can be viewed as having a stake in this type of questions. This emerges at a very general level if we consider that European citizens may have an 
interest in the moral and political integrity of the Union. More pragmatically, respect of those fundamental values is instrumental to a correct functioning of the single market and the area of freedom, security and justice for breaches of fundamental rights may deter movement towards a jurisdiction and encourage migration towards others. Moreover, given the interconnections between supranational and national decision-making, preserving national democratic processes from toxic elements is a way also of ensuring the democratic credentials of the EU institutions and political process. This is why Hungary matters not only for Hungarians but also for European citizens at large. And this is why, if European citizens are really affected by the authoritarian slide in one country, it is also up to them to react, especially when, as it is the case now, other institutional actors seem hesitant.

Jan-Werner Müller is quite right in saying that so far the responses to the Hungarian crisis have not been convincing. Several courses of action have been endeavoured but none of them seems to satisfy all the above requirements. The Venice Commission of the Council of Europe has issued important opinions on the new constitution and its implementing and amending instruments, but their impact has been minimal. The European Commission has opened a number of infringement proceedings on selected topics but also in this regard the record is mixed. On the one hand, this type of initiatives yield better results in terms of effectiveness. On the other, they fail dramatically in civic engagement. Infringement proceedings require the Commission to formulate separately its charges in well-targeted initiatives addressing the specific criticalities of the constitution and its implementing or amending legislation. Once fragmented, the debate on the new constitution loses political and constitutional pathos. The problem is no longer the political project behind the constitution, its controversial genesis and its potentially negative impact on democratic life. As the focus shifts to policing single legal initiatives, the broad picture remains in the background and all the discussion is reconfigured in more professional and technical terms within distinct administrative dossiers. Finally, also political reactions have been unfruitful. In terms of effectiveness, the European Parliament has failed to promote an article 7 TEU procedure and approved only two innocuous resolutions. [3] Moreover, the debate leading to the adoption of those documents has revealed a structural incapacity of this body to rise above party lines on behalf of constitutional democracy.[4]

So, do we need a Copenhagen Commission? In my view, this is not a good idea. Undoubtedly, the new democracy watchdog would certainly be independent and high profile. If endowed with the remedies envisaged by its proponent, it could also improve the effectiveness of the EU enforcement mechanisms. Unfortunately, a Copenhagen Commission and other similarly minded proposals would fail in terms of civic engagement. This is not only, as Komárek rightly notes, because European citizens would perceive it as another example of institutional self-aggrandizement by the EU. I am also afraid that the proliferation of institutions and procedures operating in this terrain could give rise to contradictions and, ultimately, institutional struggles (Also in this respect it cannot be pluralism all the way down). Besides, I am afraid that the idea of entrusting the delicate task of investigating, monitoring and sanctioning breaches to fundamental rights to expert bodies would probably be perceived as another instance of technocratic depoliticisation undertaken by the EU - all the more if the new institution were to use the managerial devices (scoreboards, multi-coloured flags, etc.) suggested by Floris de Witte.

This is why we should insist on what we already have - the enforcement system provided by article 7 TEU and, perhaps, make use of our creativity to improve it. In this respect, my view differs significantly from Müller's. I am not persuaded by his arguments that this instrument is unusable and I believe that the difficulties encountered so far have mostly to do with political rather than institutional failures. Let's consider article 7 in the light of our requirements. First of all, it is a system that scores quite well in terms of impartiality and authority thanks to the high voting thresholds required for its activation. Admittedly, there is a lot of justified criticism on this point and, yes, this is probably the main obstacle preventing an action against Hungary. Yet, before dismissing supermajorities all too rapidly, we should consider that they act as important safeguards against arbitrary or far-fetched political initiatives. It might be difficult to achieve the required broad consensus but, once reached, the action could vaunt an authority far more superior to that of the routine infringement proceeding or the occasional parliamentary resolution. Secondly, article 7 has the potential to mobilise European citizens. True, citizens are not directly involved for the system relies essentially on the vicarious role of EU political institutions. Yet, due to its extraordinary nature, article 7 has the capacity to dramatise the debate and capture media and citizens' attention. Unlike infringement proceedings, it deals with alleged breaches of EU fundamental 
values comprehensively. Their discussion is framed in a political context through constitutional language without resorting to expert bodies and managerialism (although nothing prevents the EU agency of Fundamental Rights to be involved as an auxiliary body). Thirdly, the amount of political pressure exerted through this procedure can be sufficient to induce constitutional self-reflection, probably even without making use of the suspension of voting rights of the defaulting country.

Of course, defence of the existing enforcement mechanism cannot be blind to its deficiencies. Looking at its effectiveness, for instance, it could be wise to allow the Council to adopt 'smart sanctions' already before egregious violations have materialised. Consideration should also be given to the expulsion of recalcitrant members as last resort option, although one should ponder carefully whether it is worth abandoning completely a country to its authoritarian destiny (Belarus is a case in point).

Finally, also the risk of inaction requires to be tackled. As explained, I am reluctant to suggest the lowering of the existing voting thresholds (To understand why, imagine the nightmare scenario of a national conservative government charged under article 7 by left leaning EU institutions). What we need, instead, is a way to overcome existing political deadlock and, possibly, engage more directly European citizens.

Following this line of thought, here is a proposal for the amendment of article 7 TEU. As it will soon appear, it draws from another instrument contained in the Lisbon Treaty, the European citizens' initiative. As widely known, article 11.4 TEU offers to one million citizens from a significant number of member states the possibility to formulate the proposal for a legal act and submit it to the attention of the Commission. Underlying this instrument is the notion that particular initiatives backed by significant popular support (1 million signatories is just the minimum threshold) could make their way through the intricacies of the EU political process. But how can this relate to the enforcement of EU values? I am not arguing here that this instrument could be used to cope with the Hungarian challenge. My interest in the European citizens' initiative, instead, is on its mode of activation of the Commission which, I think, could easily be adapted also to the initiative phase of article 7. Following article 11 TEU and its implementing regulation, we could imagine that, in case of violation (or risk of) of EU fundamental values, a sufficient number of European citizens, coming from a minimum number of member states - the regulation indicates one-fourth, but in parallel with article 7 TEU we might suggest one-third - could propose to the Commission the opening of an enforcement procedure. The Commission would not be obliged to act but, as it happens with the citizens' initiative, it should be required to receive the promoters and, if necessary, justify its lack of action (see article 10, Regulation 211/2011). This is the general idea which, clearly, relies considerably on the capacity of citizens' mobilisation to overcome institutional stalemate not only at the initiative stage of article 7 , but also in the subsequent ones. At the same time, it seems to me that this procedure protects the use of article 7 from populist or opportunistic drifts. There are also important details of the proposal deserving careful consideration. For instance, for a citizens' initiative to be successfully presented, regulation 211/2011 establishes a minimum number of signatories in at least one-quarter of the member states calculated with regard to the MEPs number of that country (article 7). A similar formula could be replicated in a new version of article 7 TEU but, in order to render more meaningful the initiative, adequate consideration should be given to requiring that a significant amount of signatures be necessarily collected in the charged member state.

A last word. As said, this is a proposal to amend article 7 TEU, although one may speculate on whether the Commission could adopt ex officio a communication anticipating this system. What is sure, however, is that Hungary cannot wait for the next treaty amendment. Thus, what can we do effectively to take action? It seems to me that nothing prevents now European citizens to mobilise and promote a similar initiative without waiting for some distant institutional reform. I wonder whether some of the hesitations of EU political institutions could be overcome if, say, a petition supported by one million European citizens to open an article 7 procedure against Hungary would arrive at their desks in the coming weeks.

[1] For a critique see C. Mouffe, On the Political (Routledge, 2005).

[2] I have developed this idea in The 'Partisan Constitution' and the corrosion of European constitutional culture, in R. Toniatti and M. Dani (eds), The Partisan Constitution - The Fundamental Law of Hungary and European Constitutional Culture (forthcoming). 
[3] See European Parliament Resolution of 5 July on the Revised Hungarian Constitution and European Parliament Resolution of 16 February 2012 on the recent political developments in Hungary.

[4] See European Parliament, debate of 8 June 2011, 11. Revised Hungarian constitution.

\section{LICENSED UNDER CC BY NC ND}

SUGGESTED CITATION Dani, Marco: Opening the enforcement of EU fundamental values to European citizens, VerfBlog, 2013/4/07, http://verfassungsblog.de/opening-the-enforcement-of-eu-fundamental-values-toeuropean-citizens/. 